\title{
One World, One Health, One Medicine: An Assessment of Intersectoral Collaboration in Avian Influenza Control in Lagos State
}

\author{
Abimbola Aman-Oloniyo*1, Olalekan Allison² and Musbau A. Razaq ${ }^{3}$ \\ 'Lagos State Ministry of Health, Nigeria; ${ }^{2}$ Lagos State Ministry of Agriculture and Cooperatives, Nigeria; ${ }^{3}$ Lagos State Ministry of \\ Information, Nigeria
}

\section{Objective}

To assess the collaborative efforts in Avian Influenza control that could be harnessed for the control of other Zoonotic diseases.

\section{Introduction}

The livestock sector is vital to the socio-economic development of Nigeria; it contributes about $9-10 \%$ of agricultural GDP. Livestock represents an important source of high quality animal protein providing about $36.5 \%$ of total protein intake of Nigerians (1). Lagos State, located in the south-western part of Nigeria, has the smallest landmass (3577 sq. km) and the highest human population density (2519.75 per sq. km) in the Country (2). The State has a poultry population of 2.5 million birds and the largest outlet for poultry products with 207 Live bird markets, 375 poultry farms and a large number of poultry products consumers (3). Avian influenza ("bird flu") is an infectious disease of birds caused by type A strains of the influenza virus. The infection is known to cross species barrier to infect humans (4). Between March 2006 and September 2007 Avian influenza (AI) outbreaks occurred in 99 poultry farms in Lagos State (3). The only human case of AI in Nigeria was detected at a health facility in Lagos in January 2007.

\section{Methods}

Following the AI outbreaks in Nigeria, a lot of human and material resources were devoted to the control of AI in the Health, Information and Veterinary sectors at all levels of administration. A desk review of the AI response activities and collaborative efforts at the State level was conducted.

\section{Results}

The inter-ministerial State Steering Committee and State Technical Committee on Avian Influenza (STCAI) were established comprising of stakeholders in the Health, Information and Veterinary sectors drawn from public and private institutions. A number of interventions were carried out including formation of Public enlightenment, Health and Veterinary sub-committees to deal with sector-specific issues. Also, reconstitution and training of State and local council Epidemic Response Teams (ERT), training/retraining of State and local council Health, Information and Veterinary officers on Epidemic Preparedness and Response to Avian Influenza, establishment and equipping of desk offices in the State departments of Health, Veterinary and Information, and appointment of AI desk officers the local council level. These interventions facilitated the conduct of joint surveillance of poultry and live bird markets by stakeholders, joint outbreak investigation and response, joint sensitization of Human and animal Health workers on AI, joint public enlightenment and community/grassroots mobilization activities (including advocacy visits to local government council administrators, traditional leaders and trade union leaders) on Avian Influenza Control. All of these were instrumental in the quick containment of $\mathrm{AI}$ in Lagos State.

\section{Conclusions}

The collaboration between Health, Information and Veterinary departments following the AI epidemic helped to curb the disease within the State. A good structure has been put in place for control of AI that can be harnessed for the control of other Zoonotic diseases in the spirit of One World, One Health, One Medicine (OWOHOM).

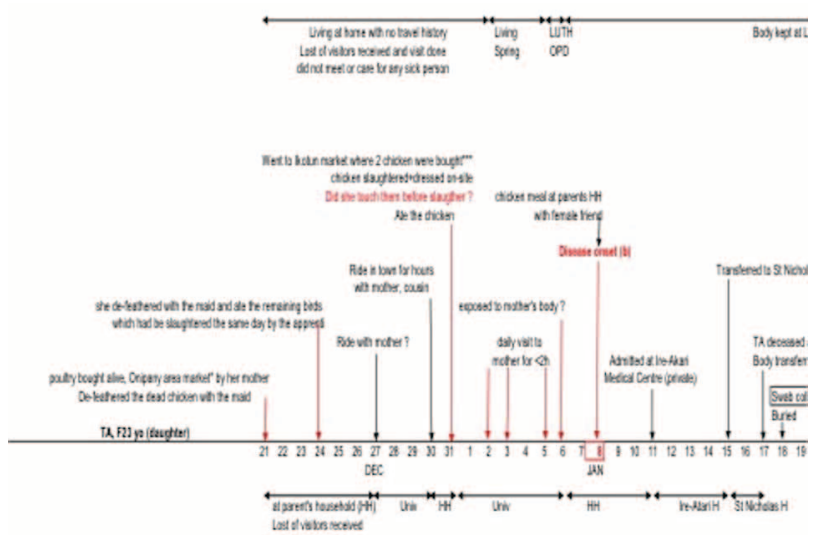

Figure 1. Clinico-Epidemic Curve of the Investigated Human Case of Avian Influenza.

\section{Keywords}

Collaborate; Avian Influenza; Zoonotic

\section{References}

1. The Integrated National Avian and Pandemic Influenza Response Plan, 2007. 3, 19 - 23

2. Reducing Health Disparities in Lagos State- An investment case, 2012. 7-8

3. Lagos State Ministry of Agriculture and Cooperatives, 2009.

4. World Health Organization. Avian Influenza fact sheet. <www.who. int $/$ mediacentre/factsheets/avian influenza/en/>. Accessed July 30, 2007.

5. World Health Organization. Cumulative number of confirmed human cases of avian influenza $\mathrm{A} /(\mathrm{H} 5 \mathrm{~N} 1)$ reported to WHO. <http://www. who.int/csr/disease/avian_influenza/country /cases_table2007_07_25/ en/index.html>. Accessed July 30, 2007.

\section{*Abimbola Aman-Oloniyo}

E-mail: bimskoms@yahoo.com 